\title{
PERFIL SENSORIAL E ACEITABILIDADE DE CULTIVARES DE FEIJÃO (Phaseolus vulgaris L.) ${ }^{1}$
}

\author{
Joel Camilo Souza CARNEIRO², Valéria Paula Rodrigues MINIM ${ }^{2, *}$, Manoel Messias de SOUZA Jr. ${ }^{2}$,
}

\author{
José Eustáquio Souza CARNEIRO ${ }^{3}$, Geraldo Antônio Andrade ARAÚJO3
}

\begin{abstract}
RESUMO
No Brasil a recomendação de novos cultivares de feijão tem sido feita em função de suas características agronômicas. Porém, nos últimos anos os pesquisadores do Programa de Melhoramento Genético do Feijoeiro têm reconhecido a importância das características tecnológicas, principalmente o perfil sensorial, dos grãos de cultivares de feijão na sua aceitação pelos consumidores. Assim, fica evidente a necessidade da caracterização sensorial dos grãos de cultivares de feijão que já são recomendados para o cultivo e daqueles que estão para serem recomendados. O presente trabalho teve como objetivo a avaliação sensorial dos grãos de sete variedades de feijão recomendadas para o Estado de Minas Gerais (Ouro Negro, Meia Noite, Carioca, Aporé, Rudá, Pérola e Vermelhinho) e de três linhagens promissoras para lançamento (MA733327, Vermelho2157 e CB733812). Estas variedades e linhagens foram produzidas pela UFV. Todas as amostras foram cozidas em panela de pressão por 23 minutos e servidas aos provadores. Análise descritiva quantitativa foi aplicada para verificar similaridades e diferenças na aparência, aroma, sabor e textura dos grãos de feijão. As amostras de feijão foram avaliadas por uma equipe composta por oito provadores previamente selecionados e treinados. Foi avaliada também a aceitabilidade das dez amostras, onde cada uma foi degustada por 30 consumidores de feijão, em condições laboratoriais, tomados ao acaso nas proximidades do laboratório de análise sensorial (DTA/UFV). Para o teste afetivo, as amostras foram temperadas. Os dez cultivares de feijão diferiram significativamente $(p<0,05)$ em relação aos atributos sensoriais definidos pelos provadores (Grãos com Ruptura do Tegumento, Cor Marrom, Cor Preta, Uniformidade da Cor, Sabor Característico, Gosto Amargo, Dureza, Granulosidade e Casca Residual), exceto para o atributo Sabor Adocicado. As linhagens apresentaram perfis sensoriais semelhantes aos das variedades, exceto para a Uniformidade da Cor (linhagem Vermelho2157), Dureza e Granulosidade (linhagens CB733812 e MA733327) e Casca Residual (linhagem CB733812). Tais caracteristicas precisam ser modificadas antes de recomendar as linhagens para cultivo. A maioria dos consumidores atribuíram escores 7 ou 8 para a aceitação dos cultivares de feijão. Não houve diferença significativa $(p>0,05)$ na aceitação dos cultivares. Todos tiveram boa aceitação e situaram-se entre os termos hedônicos "gostei moderadamente e gostei muito".

Palavras-chave: feijão; análise sensorial; análise descritiva quantitativa.
\end{abstract}

\section{SUMMARY}

SENSORY PROFILE AND ACCEPTABILITY OF CULTIVARS OF BEANS (Phaseolus vulgaris L.). In Brazil the recommendation of new cultivars of beans has been done according to the grains agronomic characteristics. However, in the last years researchers of the Genetic Improvement of Beans Program have recognized the importance of technological characteristics, mainly the sensory profile of cultivars of beans and their acceptance by consumers. So, it makes evident the need for sensory characterization of the cultivars of beans that are already suggested to cultivation and those that are ready to be. The present work aimed at carrying out the sensory evaluation of seven kinds of beans grains recommended to the State of Minas Gerais (Ouro Negro, Meia Noite, Carioca, Aporé, Rudá, Pérola, and Vermelhinho) and of three promising pure lines for releasing (MA733327, Vermelho2157, and CB733812). These cultivars and pure lines were produced by the UFV. All the samples were cooked in pressure cooker for 23 minutes and served to the tasters. Quantitative descriptive analysis was applied to verify similarities and differences in the appearance, smell, flavor, and texture of the beans. A panel composed by eight tasters, who were previously selected and trained, evaluated the samples of beans. The sensory acceptability of the ten samples was also evaluated by 30 consumers, picked randomly near the sensory analysis laboratory (DTA/UFV). To the affective test, the samples were spiced. The ten cultivars of beans differed significantly $(p<0,05)$ in relation to the sensory attributes defined by the panel (Grains with Tegument Rupture, Brown Color, Black Color, Color Uniformity, Characteristic Flavor, Bitter Taste, Hardness, Granularity, and Residual Skin), except for the attribute Sweetened Flavor. The lines presented sensory profile similar to the kinds, except for Color Uniformity (line Vermelho2157), Hardness e Granularity (lines CB733812 and MA733327) and Residual Skin (line CB733812). These characteristics need to be modified before to recommend the lines for cultivation. The majority of the consumers gave scores 7 or 8 for beans cultivars acceptance. There was no significant difference $(p>0,05)$ in the acceptability of the cultivars. All of them had positive acceptance and were rated within the hedonic terms "liked moderately" and "liked very much." Keywords: beans; sensory analysis; and quantitative descriptive analysis.

\section{1 - INTRODUÇÃO}

O feijoeiro (Phaseolus vulgaris L.) é a planta originária do Novo Mundo e cultivada, atualmente, em todos os continentes [4]. Vale salientar o grande número de variedades de feijão (Phaseolus vulgaris), tais como fei-

1. Recebido para publicação em 02/07/2002. Aceito para publicação em 21/12/2004 (000872).

2. Departamento de Tecnologia de Alimentos (DTA) - Universidade Federal de Viçosa (UFV) . CEP: 36571-000, Viçosa-MG, Brasil. Telefone: (31) 3899 1623. E-mail: vprm@mail.ufv.br

3. Departamento de Fitotecnia - Universidade Federal de Viçosa (UFV). CEP: 36571-000, Viçosa-MG, Brasil.

* A quem a correspondência deve ser enviada. jão-preto, feijão-mulatinho, feijão-carioquinha, feijãopardo, feijão-roxinho, entre outros [10].

Entre as culturas de grãos, o feijoeiro é a que exibe o mais alto nível de variabilidade quanto à cor, tamanho e forma da semente, sendo que estas características influenciam as pessoas quanto à preferência por determinada variedade. Segundo GUEVARA [6], no Brasil há maior aceitação dos feijões de sementes pequenas e opacas. O feijão preto é mais popular no Rio Grande do Sul, Santa Catarina, sul e leste do Paraná, Rio de Janeiro, sudeste de Minas Gerais e sul do Espírito Santo. No restante do país, este tipo de grão tem pouco ou quase nenhum valor comercial ou aceitação. O feijão do tipo carioca é aceito em praticamente todo o país. 
O Brasil é um dos maiores produtores e consumidores de feijão. Apesar da grande produção e consumo, há carência de estudos que caracterizam aparência, aroma, textura e sabor dos grãos das diversas variedades de feijão, ou seja, na maioria das vezes não se conhece o perfil sensorial dos grãos de feijão, principalmente daquelas variedades melhoradas geneticamente. Há alguns estudos envolvendo a avaliação sensorial de feijão, a exemplo tem-se os trabalhos [1, 3, 12]. No Brasil, a recomendação de novos cultivares de feijão tem sido feita em função de suas características agronômicas. Algumas delas são a produtividade e resistência às principais doenças que atacam o feijoeiro. Porém, nos últimos anos os pesquisadores do Programa de Melhoramento Genético do Feijoeiro têm reconhecido a importância das características físicas e sensoriais dos grãos de cultivares de feijão na sua aceitação pelos consumidores.

A Análise Descritiva Quantitativa (ADQ) é um método de avaliação sensorial que identifica, descreve e quantifica os atributos sensoriais de um produto [5], isto é, ele descreve as propriedades sensoriais e mede a intensidade em que elas foram percebidas pelos provadores. Esta metodologia permite a descrição das características sensoriais com precisão em termos matemáticos [9].

A determinação da aceitação pelo consumidor é parte crucial no processo de desenvolvimento ou melhoramento de produtos. Para uma triagem inicial ou uma avaliação preliminar da aceitação, a análise é normalmente realizada em condições laboratoriais, com 30-50 julgadores não-treinados. Entre os métodos mais empregados para medida da aceitação de produtos está a Escala Hedônica. Nesta escala o provador expressa sua aceitação pelo produto, seguindo uma escala previamente estabelecida que varia gradativamente com base nos atributos "gosta e desgosta".

Este estudo teve como objetivo aplicar a técnica Análise Descritiva Quantitativa para desenvolver o perfil sensorial e aceitabilidade dos grãos de algumas cultivares de feijão. Para tal, foram utilizados grãos de algumas das variedades de feijão recomendadas para o Estado de Minas Gerais (Ouro Negro, Meia Noite, Carioca, Aporé, Rudá, Pérola e Vermelhinho) e das linhagens promissoras para lançamento no mesmo Estado (MA733327, Vermelho2157 e CB733812).

\section{2 - MATERIAL E MÉTODOS}

\section{1 - Material}

Os cultivares de feijão utilizados neste estudo foram fornecidos pelo Departamento de Fitotecnia, setor de Genética e Melhoramento de Plantas da Universidade Federal de Viçosa (UFV). Foram utilizados grãos da safra de 1997, plantados em campo experimental da UFV, na cidade de Viçosa - MG.

Foram avaliados grãos de algumas das variedades de feijão recomendadas para o Estado de Minas Gerais (Ouro
Negro, Meia Noite, Carioca, Aporé, Rudá, Pérola e Vermelhinho) e das linhagens promissoras para lançamento no mesmo Estado (MA733327, Vermelho2157 e CB733812). Os cultivares Ouro Negro, Meia Noite e MA733327 pertencem ao grupo comercial preto. O Carioca, Pérola e Aporé pertencem ao grupo Carioca e o Vermelhinho, Vermelho2157 e CB73312 pertencem ao grupo vermelho.

Os grãos foram colhidos em julho de 1997, secos ao sol até atingir umidade em torno de 14\%, espurgados e selecionados os grãos integros para se proceder à avaliação sensorial. Para minimizar as alterações físico-químicas e sensoriais dos grãos até se proceder à análise sensorial, amostras de feijão de cada cultivar foram colocadas em sacos de polietileno, envoltos em papel alumínio e mantidos em geladeira à temperatura em torno de $5^{\circ} \mathrm{C}$. O feijão permaneceu nestas condições por aproximadamente seis meses, quando foram concluídas as avaliações.

\section{2 - Análise Descritiva Quantitativa (ADQ)}

O método empregado é uma adaptação da Análise Descritiva Quantitativa desenvolvida por STONE \& SIDEL [13], que permite descrever as principais características que compõem a aparência, aroma, textura e sabor de um alimento, além de medir a intensidade das sensações percebidas.

\subsection{1 - Condições do teste}

A ADQ foi realizada no laboratório de Análise Sensorial do Departamento de Tecnologia de Alimentos da Universidade Federal de Viçosa (DTA/UFV), em cabines individuais, com utilização de luz vermelha, para avaliar aroma, sabor e textura. A luz vermelha foi utilizada para mascarar diferenças na aparência que possam influenciar o provador na percepção do sabor e textura. A aparência foi avaliada fora da cabine, com iluminação natural.

\subsection{2 - Preparo e apresentação das amostras}

Amostras de $300 \mathrm{~g}$ de feijão, de cada cultivar, foram macerados em 1500mL de água purificada (Purificador Europa), por oito horas, a temperatura ambiente.

Separou-se a água dos grãos e a colocou em panela de pressão levando-se ao aquecimento até levantar fervura. Em seguida, adicionou-se os grãos e esperouse nova fervura. A panela foi tampada, com o feijão sendo cozido sob pressão por 23 minutos.

Para avaliação em relação ao aroma, sabor, e textura, aproximadamente 40 gramas de cada amostra foram servidas em pires de fundo preto codificados com números de três dígitos.

A aparência das amostras foi avaliada fora da cabine, com iluminação natural, sendo as amostras servidas em pires branco e codificado com números aleatórios de três dígitos.

\subsection{3 - Equipe sensorial}

Foram recrutados voluntários para comporem a equipe sensorial, dentre funcionários e estudantes da Uni- 
versidade Federal de Viçosa. Foram recrutados candidatos que dispunham de tempo, gozavam de boa saúde, que gostavam de feijão e que tinham capacidade de utilizar termos descritivos.

A habilidade de cada indivíduo em discriminar sensorialmente diferentes amostras de feijão foi julgada, aplicando-se para cada indivíduo, uma série de testes triangulares e selecionando-se os provadores que acertaram, no mínimo, 50\% dos testes realizados. Este percentual mínimo de acertos atende a recomendação de MEILGARD, CIVILLE \& CARR [7] que é de 40\%.

Para realização da série de testes triangulares, foram utilizados grãos dos cultivares Ouro Negro e Meia Noite cozidos em diferentes tempos, evidenciando a diferença de textura e sabor entre as amostras.

a) Levantamento de terminologia descritiva e treinamento dos provadores

A terminologia descritiva foi levantada aplicandose o método de rede ("The Kelly Repertory Grid Method") [8]. As amostras foram apresentadas aos pares: Pérola x Carioca; Aporé x Rudá; Carioca x Ouro Negro; MA733327 x Meia Noite; Ouro Negro x Meia Noite; Carioca $\mathrm{x}$ Vermelhinho; Vermelhinho x Vermelho 2157; Vermelho 2157 x CB733812; Ouro Negro x CB733812. Foi solicitado aos provadores, em cada sessão, que avaliassem individualmente dois pares de amostras e que descrevessem similaridades e diferenças entre as amostras de cada par. Após as avaliações individuais procedeu-se a uma descrição dos termos levantados por cada provador. Em seguida, de posse de uma ampla lista de termos levantados, sob a supervisão de um líder da equipe (moderador) os provadores discutiram o significado de cada termo, eliminaram termos correlatos, agruparam termos sinônimos. Materiais de referência foram providenciados para cada termo descritivo levantado, visando o treinamento dos provadores na utilização de cada termo descritivo. Assim, após a realização de várias sessões, uma ficha de avaliação, uma lista de referência e uma definição de cada termo descritivo foram obtidos por consenso da equipe sensorial.

\section{b) Seleção dos provadores}

Foram escolhidas, para seleção dos provadores, as amostras Aporé e MA733327. Cada provador avaliou as duas amostras em três repetições, sendo selecionados de acordo com a repetibilidade dos resultados. Foram realizadas análises de variância (ANOVA) de dois fatores (repetições e amostras) para cada provador por atributo [11]. Foram eliminados os provadores que apresentaram probabilidade $\mathrm{F}_{\text {repetiçōes }}$ menores que 0,05 em pelo menos um dos atributos. Após esta seleção final, obteve-se uma equipe de oito provadores para a avaliação das amostras teste.

\section{c) Avaliação das amostras}

Utilizando os atributos levantados, oito provadores selecionados e treinados avaliaram as amostras.

Para o delineamento experimental, optou-se pelo delineamento de blocos incompletos balanceados para dez amostras [2] com os seguintes parâmetros:
- $\mathrm{t}$ : número de tratamentos $=10$

- $\mathrm{k}$ : número de unidades por bloco $=3$

- $\quad$ r: número de repetições $=9$

- b: número de blocos $=30$

- $\quad \lambda$ : número de vezes que cada tratamento aparece no mesmo bloco com cada um dos outros tratamentos $=2$

- $\quad$ E: grau de eficiência do delineamento $=0,74$

\section{3 - Teste de aceitação}

Os testes de aceitação foram realizados no laboratório de Análise Sensorial do Departamento de Tecnologia de Alimentos da Universidade Federal de Viçosa (DTA/UFV), em cabines individuais, pela manhã (entre 9:30 e 11:00 horas) e pela tarde (entre 14:30 e 17:00 horas).

O feijão foi cozido da mesma forma do que foi utilizado para a ADQ (conforme item 2.2.2). Em seguida, refogado em óleo de soja, alho e sal, mantendo-se sob fervura até o caldo atingir uma consistência pré-determinada.

As amostras foram avaliadas por diferentes grupos de consumidores, cada grupo composto por 30 pessoas. A distribuição das amostras, por grupo, foi feita de forma aleatória. O feijão foi servido 40 gramas de amostra para cada consumidor. Os consumidores utilizaram a escala hedônica de nove pontos para a avaliação.

\section{4 - Análise dos resultados}

Todas as análises estatísticas foram realizadas em microcomputador, utilizando programas do pacote estatístico SAS (SAS Institute Inc. North Carolina).

Os dados obtidos pela Análise Descritiva Quantitativa foram avaliados da seguinte forma:

- Análise do perfil sensorial das amostras através do gráfico Aranha;

- Análise de variância com interação para avaliação das amostras. A significância estatística das diferenças entre as médias foi determinada mediante teste de Tukey.

Foi realizada a distribuição de freqüência dos escores atribuídos para aceitação de cada cultivar de feijão. Os dados do teste de aceitação foram submetidos, também, a análise de variância e teste de Tukey.

\section{3 - RESULTADOS E DISCUSSÃO}

Dos 29 voluntários, apenas 16 foram selecionados para participarem do processo de desenvolvimento de terminologia descritiva.

Após ter sido levantada uma ampla lista de termos descritivos chegou-se, por consenso entre todos os provadores, a 10 descritores que caracterizavam as amostras de feijão (Tabela 1) e uma ficha de avaliação foi elaborada (Figura 1). 
TABELA 1. Definições dos termos descritivos e referências para as amostras de feijão.

\begin{tabular}{|c|c|}
\hline Descritores & Definições e referências \\
\hline Ruptura do Tegumento & $\begin{array}{l}\text { Quebra do tegumento do feijão causada pelo cozimento. } \\
\text { Referência: Nenhum: CB733812 cozido por } 21 \text { minutos } \\
\text { Todos - Ouro Negro cozido por } 25 \text { minutos }\end{array}$ \\
\hline Cor Marrom & $\begin{array}{l}\text { Cor apresentada pelo tegumento. Impressão produzida no } \\
\text { órgão visual pelos raios da luz decomposta. } \\
\text { Referência: Clara - Engopa Ouro } \\
\text { Média - Vermelho } 2157 \\
\text { Escura - XAN } 235\end{array}$ \\
\hline Cor Preta & $\begin{array}{l}\text { Cor apresentada pelo tegumento. Impressão produzida no } \\
\text { órgão visual pelos raios da luz decomposta. } \\
\text { Referência: Clara: Feijão Vagem } \\
\text { Escura: Ouro Negro }\end{array}$ \\
\hline Uniformidade da Cor & $\begin{array}{l}\text { Presença de apenas uma tonalidade de cor no tegumento. } \\
\text { Referência: Pouca: Vermelhinho + CB733812 } \\
\text { Muita: Vermelhinho }\end{array}$ \\
\hline Sabor Característico & $\begin{array}{l}\text { Atributo de sabor característico de feijão cozido. } \\
\text { Referência: Pouco - manteigão (Ouro Branco) } \\
\text { Muito: - grupo carioca (Pérola) }\end{array}$ \\
\hline Sabor Adocicado & $\begin{array}{l}\text { Atributo de sabor associado à sacarose. } \\
\text { Referência: Ausente - Pérola } \\
\text { Forte - Ouro Negro, macerado em solução } 5 \% \text { de sacarose } \\
\text { antes da cocção }\end{array}$ \\
\hline Gosto Amargo & $\begin{array}{l}\text { Atributo de sabor associado a Hidrocloreto de Quinina } \\
\text { Referência: Ausente - Pérola } \\
\text { Forte - Meia Noite, sendo adicionado } 1 \mathrm{~mL} \text { de solução } 0,2 \% \\
\text { de Hidrocloreto de Quinina para } 100 \mathrm{~mL} \text { de caldo }\end{array}$ \\
\hline Dureza & $\begin{array}{l}\text { Julgada sensorialmente como a força necessária para } \\
\text { penetrar uma substância com o dente molar. Quanto maior } \\
\text { a força para romper os grãos de feijão, maior é a sua } \\
\text { dureza. } \\
\text { Referência: Pouca - Ouro Negro cozido por } 25 \text { minutos } \\
\text { Muita - CB733812 cozido por } 21 \text { minutos }\end{array}$ \\
\hline Granulosidade & $\begin{array}{l}\text { Presença de grânulos grosseiros observados durante a } \\
\text { mastigação. } \\
\text { Referência: Ausente - Ouro Negro cozido por } 25 \text { minutos } \\
\text { Muita - CB733812 cozido por } 21 \text { minutos }\end{array}$ \\
\hline Casca Residual & $\begin{array}{l}\text { Presença de casca na boca após a mastigação. } \\
\text { Referência: Pouca - Ouro Negro cozido por } 25 \text { minutos } \\
\text { Muita - CB733812 cozido por } 21 \text { minutos }\end{array}$ \\
\hline
\end{tabular}

Todos os feijões utilizados como referência foram apresentados cozidos. O cozimento foi feito em panela de pressão.

Foram selecionados, para a avaliação final das amostras, oito provadores cujos niveis de significância de $\mathrm{F}_{\text {repetiçōes }}$ foram superiores a 0,05 em todos os atributos (Tabela 2), sendo sete homens e uma mulher, com faixa etária entre 20 a 40 anos.

As Figuras 2 e 3 sugerem que houve diferença entre os perfis sensoriais dos grãos dos cultivares de feijão avaliados. O gráfico aranha é utilizado para uma melhor visualização do perfil sensorial dos cultivares de feijão. Para verificar se realmente houve diferença entre os perfis sensoriais, realizou-se ANOVA e os resultados demonstraram que existiu diferença $(p \leq 0,05)$ entre pelo menos 2 amostras em todos os atributos avaliados.

$\mathrm{Na}$ Tabela 3 estão apresentadas as médias dos atributos sensoriais para os cultivares de feijão.

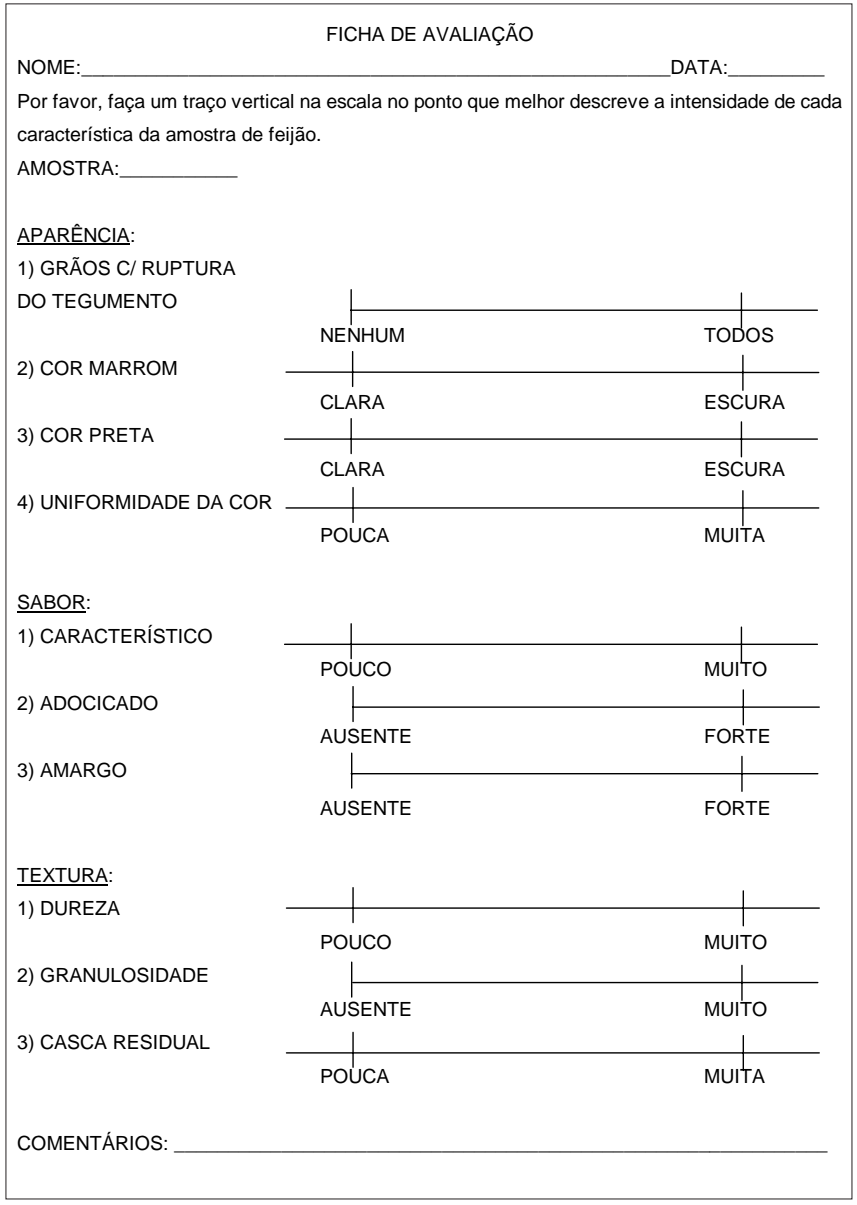

FIGURA 1. Ficha de avaliação sensorial (ADQ) para os cultivares de feijão.

TABELA 2. Valores de nível de significância de $\mathrm{F}_{\text {repetiçōes }}$ da análise de variância para os provadores selecionados.

\begin{tabular}{lcccccccc}
\hline \multirow{2}{*}{ ATRIBUTOS } & \multicolumn{10}{c}{ PROVADORES } \\
\cline { 2 - 9 } & $\mathrm{P}_{2}$ & $\mathrm{P}_{3}$ & $\mathrm{P}_{4}$ & $\mathrm{P}_{6}$ & $\mathrm{P}_{7}$ & $\mathrm{P}_{8}$ & $\mathrm{P}_{9}$ & $\mathrm{P}_{10}$ \\
\hline Ruptura do tegumento & 0,80 & 0,06 & 0,23 & 0,39 & 0,15 & 0,32 & 0,14 & 0,63 \\
Cor Marrom & 0,50 & 0,50 & 0,50 & 0,50 & 0,50 & 0,50 & 0,50 & 0,50 \\
Cor Preta & 0,50 & 0,50 & 0,50 & 0,50 & 0,50 & 0,50 & 0,50 & 0,50 \\
Uniformidade da Cor & 0,59 & 0,65 & 0,83 & 0,99 & 0,93 & 0,68 & 0,51 & 0,57 \\
Sabor Característica & 0,92 & 0,62 & 0,89 & 0,42 & 0,28 & 0,24 & 0,07 & 0,93 \\
Sabor Adocicado & 0,29 & 0,67 & 0,31 & 0,72 & 0,84 & 0,31 & 0,60 & 0,97 \\
Gosto Amargo & 0,42 & 0,23 & 0,24 & 0,49 & 0,50 & 0,12 & 0,36 & 0,30 \\
Dureza & 0,84 & 0,31 & 0,73 & 0,78 & 0,61 & 0,37 & 0,77 & 0,58 \\
Granulosidade & 0,46 & 0,50 & 0,62 & 0,78 & 0,90 & 0,09 & 0,35 & 0,50 \\
Casca Residual & 0,55 & 0,50 & 0,68 & 0,26 & 0,81 & 0,36 & 0,80 & 0,59 \\
\hline
\end{tabular}

As variedades Ouro Negro, Meia Noite, Carioca, Aporé, Rudá, Pérola e Vermelhinho são recomendadas para cultivo no Estado de Minas Gerais. Algumas já são consumidas pelos mineiros e outras já estão começando a fazer parte de seu cardápio. As linhagens MA733327, Vermelho2157 e CB733812 precisam apresentar características sensoriais iguais ou melhores que as das variedades, pois só assim serão incluídas no cardápio dos consumidores do Estado. 
Observa-se que não houve diferença entre as amostras Ouro Negro e Pérola quanto ao atributo ruptura do tegumento. Estes dois cultivares apresentaram maior intensidade do atributo, diferindo dos demais. O cultivar CB733812 foi o que apresentou a menor quantidade de grãos com ruptura do tegumento.

A amostra CB733812 apresentou cor marrom mais escura, diferindo das demais. O Pérola e Aporé não diferiram quanto à cor marrom, e a apresentaram em menor intensidade.

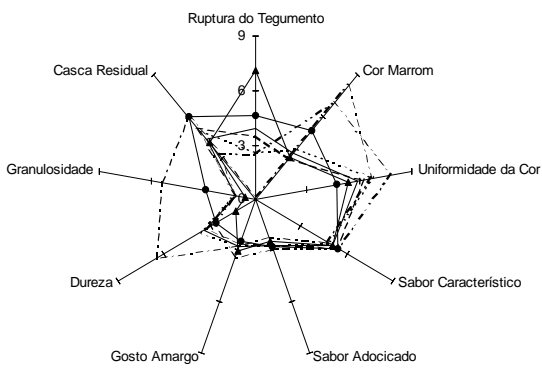

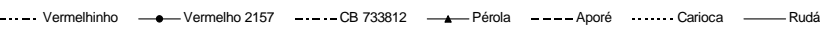

FIGURA 2. Perfil sensorial (grupos carioca e vermelho)

Os cultivares MA733327 e Ouro Negro não diferiram quanto à cor preta, mas diferiram do Meia Noite, sendo os dois primeiros os mais escuros.

Vermelhinho, Ouro Negro e MA733327 não diferiram entre si quanto à uniformidade da cor, sendo os mais uniformes. O Vermelho2157 foi o menos uniforme.

Os cultivares que apresentaram sabor característico em maior intensidade foram Vermelhinho, Vermelho2157,
Meia Noite, Ouro Negro e Aporé. O feijão MA733327 foi o que apresentou o sabor característico em menor intensidade, não diferindo do CB733812 e Carioca.

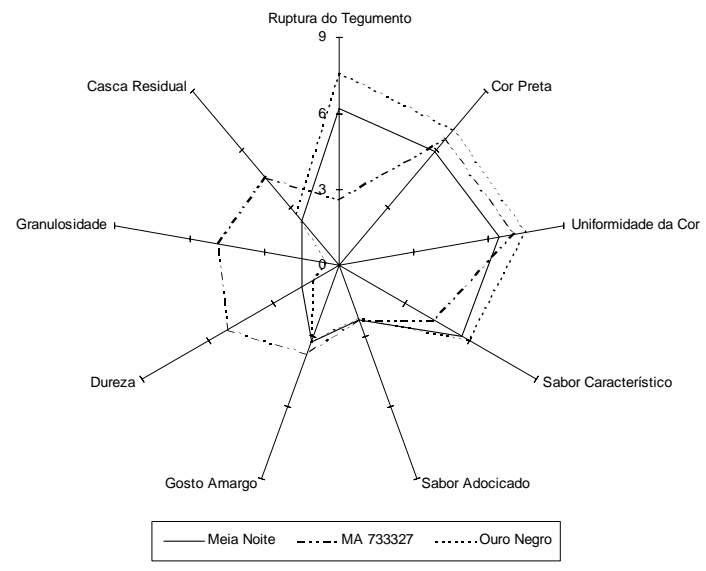

FIGURA 3. Perfil sensorial (grupos preto)

Não houve diferença entre os feijões quanto ao sabor adocicado e a média variou de 2,2 a 2,9.

Em relação ao gosto amargo, a amostra MA733327 apresentou a maior intensidade e não diferiu dos Vermelhinho, Meia Noite, Ouro Negro e Pérola.

O feijão com maior intensidade de dureza foi o CB733812, diferindo dos demais. Já o Ouro Negro foi o que possuiu menor dureza, não diferindo do Pérola e Meia Noite.

Quanto à granulosidade os cultivares CB733812 e MA733327 não diferiram entre si, e foram os que apresentaram maior granulosidade.

TABELA 3. Médias dos atributos sensoriais para as amostras de feijão

\begin{tabular}{|c|c|c|c|c|c|c|c|c|c|c|}
\hline \multirow{2}{*}{ ATRIBUTO } & \multicolumn{10}{|c|}{ AMOSTRAS } \\
\hline & Vermelhin. & Verm.2157 & CB733812 & Meia Noite & MA733327 & $\begin{array}{l}\text { Ouro } \\
\text { Negro }\end{array}$ & Pérola & Aporé & Carioca & Rudá \\
\hline $\begin{array}{l}\text { Ruptura do } \\
\text { Tegumento }\end{array}$ & $2,5^{\mathrm{e}}$ & $4,6^{c}$ & $0,2^{f}$ & $6,2^{b}$ & $2,6^{\mathrm{e}}$ & $7,6^{a}$ & $7,1^{a}$ & $3,5^{d}$ & $2,6^{\mathrm{e}}$ & $3,9^{d}$ \\
\hline Cor Marrom & $6,9^{b}$ & $5,0^{c}$ & $8,2^{a}$ & --- & ---- & ---- & $3,0^{\text {ef }}$ & $2,9^{f}$ & $3,7^{d}$ & $3,3^{\text {de }}$ \\
\hline Cor Preta & ---- & ---- & ---- & $5,6^{\mathrm{b}}$ & $6,5^{\mathrm{a}}$ & $7,0^{\mathrm{a}}$ & ---- & ---- & ---- & ---- \\
\hline $\begin{array}{l}\text { Uniformidade da } \\
\text { Cor }\end{array}$ & $7,8^{a}$ & $4,7^{f}$ & $6,7^{b c}$ & $6,4^{c d}$ & $7,0^{a b c}$ & $7,5^{a b}$ & $5,3^{e f}$ & $6,3^{c d}$ & $6,8^{b c}$ & $5,9^{d e}$ \\
\hline $\begin{array}{l}\text { Sabor } \\
\text { Característico }\end{array}$ & $5,4^{a b c}$ & $5,4^{a b c d}$ & $4,7^{d e}$ & $5,6^{a b}$ & $4,3^{e}$ & $5,9^{a}$ & $5,1^{b c d}$ & $5,3^{a b c d}$ & $4,8^{c d e}$ & $5,1^{b c d}$ \\
\hline Sabor Adocicado & $2,9^{a}$ & $2,8^{a}$ & $2,2^{a}$ & $2,3^{a}$ & $2,3^{a}$ & $2,2^{a}$ & $2,5^{\mathrm{a}}$ & $2,7^{a}$ & $2,7^{\mathrm{a}}$ & $2,7^{a}$ \\
\hline Gosto Amargo & $3,4^{a b}$ & $2,5^{c}$ & $2,7^{b c}$ & $3,2^{a b c}$ & $3,7^{\mathrm{a}}$ & $3,2^{a b c}$ & $3,0^{a b c}$ & $2,6^{c}$ & $2,7^{b c}$ & $2.8^{b c}$ \\
\hline Dureza & $2,7^{\mathrm{de}}$ & $2,6^{\mathrm{e}}$ & $6,5^{a}$ & $1,7^{f}$ & $5,1^{b}$ & $1,2^{f}$ & $1,3^{f}$ & $3,2^{c d}$ & $3,6^{c}$ & $3.4^{c}$ \\
\hline Granulosidade & $1,1^{c d}$ & $2,9^{b}$ & $5,4^{a}$ & $1,5^{\mathrm{c}}$ & $4,9^{a}$ & $0,5^{d}$ & $0,6^{d}$ & $1,1^{\mathrm{cd}}$ & $1,2^{c d}$ & $1,1^{c d}$ \\
\hline Casca Residual & $3,3^{f}$ & $5,9^{a b}$ & $5,9^{a}$ & $2,3^{\mathrm{g}}$ & $4,5^{\mathrm{cde}}$ & $2,7^{f g}$ & $4,1^{e}$ & $5,2^{b c}$ & $4,9^{c d}$ & $4,3^{\mathrm{de}}$ \\
\hline
\end{tabular}

Médias com mesmo superescrito, na mesma linha, não diferem significativamente entre si $(\mathrm{p}>0,05)$.

A intensidade das caracteristicas sensoriais foram avaliadas em escala não estruturada de $9 \mathrm{~cm}$. 
Os cultivares Vermelhinho, Meia Noite e Ouro Negro foram os que tiveram menor quantidade de casca residual, diferindo dos demais.

Concentrando as informações obtidas, com ênfase nas características indesejáveis apresentadas pelas linhagens de feijão e que precisam ser melhoradas antes de sua recomendação para cultivo, tem-se:

- a linhagem Vermelho2157 foi a de menor uniformidade da cor dos grãos, diferindo da maioria das variedades;

- as linhagens CB733812 e MA733327 apresentaram muita granulosidade e alta dureza dos grãos, diferindo das variedades;

- a linhagem CB733812 apresentou maior quantidade de casca residual em relação às variedades.
A maioria dos consumidores (variando entre 56,7\% para o cultivar Ouro Negro e 90\% para o Vermelhinho) atribuíram notas 7 ou 8, na escala hedônica, para a aceitação dos cultivares de feijão (Tabela 4). Assim, todos os cultivares agradaram a maioria dos consumidores.

$\mathrm{Na}$ Tabela 5 estão apresentados os resultados da análise estatística (Teste de Tukey) dos dados do teste de aceitação para os 10 cultivares de feijão. Observase que não houve diferença na aceitação dos cultivares, a $5 \%$ de probabilidade.

Comparando as posições das médias dos escores atribuídos aos diferentes cultivares de feijão na escala hedônica, verifica-se que as médias variaram de 7,1 a 7,6 . Portanto, todos os cultivares estão situados entre os termos hedônicos "gostei moderadamente e gostei muito". O que indica uma boa aceitação.

TABELA 4. Distribuições de Freqüências das notas para aceitação dos cultivares de feijão

\begin{tabular}{|c|c|c|c|c|c|c|c|c|c|c|}
\hline \multirow{2}{*}{ NOTA } & \multicolumn{10}{|c|}{ CULTIVAR } \\
\hline & Vermelhinho & Vermelho2157 & CB733812 & Meia Noite & MA733327 & Ouro Negro & Pérola & Aporé & Carioca & Rudá \\
\hline 2 & - & - & - & - & - & - & - & - & 3,33 & - \\
\hline 4 & 3,33 & 6,67 & - & - & - & - & 3,33 & - & 3,33 & 3,33 \\
\hline 5 & - & 3,33 & 6,67 & - & - & 3,33 & 3,3 & 3,33 & - & 3,33 \\
\hline 7 & 36,67 & 36,67 & 30,00 & 40,00 & 33,33 & 23,33 & 43,33 & 26,67 & 26,67 & 40,00 \\
\hline 8 & 53,33 & 43,33 & 43,33 & 40,00 & 43,33 & 33,33 & 33,33 & 60,00 & 56,67 & 36,67 \\
\hline 9 & - & - & 6,67 & 3,33 & 10,00 & 23,33 & 13,33 & 3,33 & 3,33 & 16,67 \\
\hline
\end{tabular}

TABELA 5. Médias das notas obtidas pelo teste de aceitação para cultivares de feijão

\begin{tabular}{lc}
\hline Cultivar & Média \\
\hline Ouro Negro & $7,6^{\mathrm{a}}$ \\
Aporé & $7,5^{\mathrm{a}}$ \\
Rudá & $7,5^{\mathrm{a}}$ \\
MA733327 & $7,5^{\mathrm{a}}$ \\
Pérola & $7,4^{\mathrm{a}}$ \\
Vermelhinho & $7,4^{\mathrm{a}}$ \\
Carioca & $7,3^{\mathrm{a}}$ \\
Meia noite & $7,3^{\mathrm{a}}$ \\
CB733812 & $7,2^{\mathrm{a}}$ \\
Vermelho2157 & $7,1^{\mathrm{a}}$ \\
\hline Médias seguidas de pelo menos uma mesma letra não apresentam diferença entre si,
\end{tabular}
pelo teste de Tukey, a $5 \%$ de probabilidade.

\section{4 - CONCLUSÕES}

Os cultivares avaliados diferiram significativamente (5\% de significância) em relação aos atributos sensoriais de seus grãos (Grãos Com Ruptura do Tegumento, Cor Marrom, Cor Preta, Uniformidade da Cor, Sabor Característico, Gosto Amargo, Dureza, Granulosidade e Casca Residual), exceto para o Sabor Adocicado.

As linhagens apresentaram perfis sensoriais semelhantes aos das variedades, exceto para algumas características que precisam ser melhoradas antes de serem recomendadas para cultivo. A linhagem Vermelho2 157 precisa ser "trabalhada" de forma a apresentar grão com maior uniformidade de cor. A CB733812 e MA733327 precisam ter grãos mais macios e com menor granulosidade. É necessário, também, que haja uma redução na quantidade de casca residual da linhagem CB733812.

Não houve diferença na aceitação dos cultivares, a $5 \%$ de probabilidade. Todos os cultivares e as linhagens situaram-se dos entre os termos hedônicos "gostei moderadamente e gostei muito", indicando boa aceitação.

\section{5 - REFERÊNCIAS BIBLIOGRÁFICAS}

[1] CARNEIRO, J. C. S. Processamento industrial de feijão, avaliação sensorial descritiva e mapa de preferência. Viçosa. 2001. 90f. Dissertação (Mestrado em Ciência e Tecnologia de Alimentes) - Universidade Federal de Viçosa.

[2] COCHRAN, W.G.; COX, G.M. Disenos experimentales. 2. ed. México: Editorial Trillas, 1981. $661 \mathrm{p}$.

[3] FERRAREZI, R. S.; SANTOS, J. C. P.; GUIDOLIN, A. F.; KASCHUK, G.; COELHO, C. M. Qualidades sensoriais e acúmulo de nutrientes em grãos de feijão afetados 
por niveis de adubação. In: $2^{a}$ REUNIÃO TÉCNICA CATARINENSE DE MILHO E FEIJÃO, 1999, Lages. Resumos da $2^{\text {a }}$ Reunião Técnica Catarinense de Milho e Feijão. Florianópolis: UDESC/EPAGRI, 1999. p.250253.

[4] FONSECA, S.V.; VIEIRA, C.; MINIM, V.P.R.; CARDOSO, A.A. Folhas verdes de feijão na alimentação humana: avaliação sensorial, adubação nitrogenada e desfolhamento. Bragantia, Campinas, v.61, n.2, p.161-167, 2002

[5] GILLETE, M. Applications of descritive analysis. Journal of Food Protection; v.47, n. 5, p. 403 - 409, 1984.

[6] GUEVARA, L.L.V. Comportamento físico-sensorial de novas cultivares de feijão (Phaseolus vulgaris L.) armazenados em condições ambientais. Lavras. 1990. 132f. Dissertação (Mestrado em Ciência e Tecnologia de Alimentos) - Escola Superior de Agricultura de Lavras.

[7] Meilgard, M. CIVIlle, V.; CARR, B. T.. Sensory evaluation techniques. BOCA RATON, Florida: CRC Press, 1988. 279p.

[8] MOSKOWITZ, H.R. Product testing and sensory evaluation of foods-Marketing and $R \& D$ approaches. Westport: Food \& Nutrition Press, 1983. 605p.
[9] MOSKOWISTZ, H. R. Applied sensory analysis of foods. Boca Ratton: CRC Press, 1988. V.1, 259p.

[10] OLIVEIRA, F. E. M. de. Feijão: Curvas de absorção de água e elaboração de farinhas. Viçosa. 1997. 63f. Dissertação (Mestrado) - Universidade Federal de Viçosa.

[11] POWERS, J.J., CENCIARELli, S., SCHINHOLSER, E. El uso de programas estatisticos generales en la evaluacion de los resultados sensoriales. Revista Agroquimica y Tecnologia de Alimentos, v. 24, n. 4, p. 469-484, 1984.

[12] SANTOS, J. C. P.; KLAUBERG FILHO, O.; FERRAREZI, R. S.; BERTON JÚNIOR, J. F.; KASCHUK, G. Rendimento de grãos, acúmulo de nutrientes e avaliação sensorial de variedades comerciais e acessos crioulos de feijoeiro (Phaseolus vulgaris L.). In: FERTBIO 2000: BIODINÂMICA DO SOLO, 2000, Santa Maria. FERTBIO 2000: Biodinâmica do Solo - XXIV Reunião Brasileira de Fertilidade do Solo e Nutrição de Plantas, VIII Reunião Brasileira sobre Micorrizas, VI Simpósio Brasileiro de Microbiologia do Solo e III Reunião Brasileira de Biologia do Solo. Santa Maria: Editora Universitária - UFSM, 2000. p. 19.

[13] STONE, H.; SIDEL, J.L. Sensory evaluation practices. London: Academic Press, 1985. $311 \mathrm{p}$. 